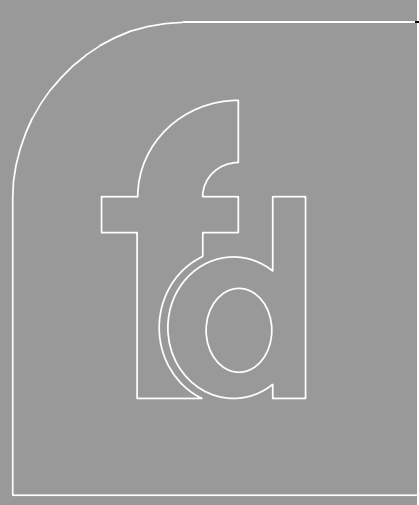

CONTENTS

Introductory oveniew

Treatment with selective serotonin reuptake inhibitors

Othertreatmentapproaches

Conclusions

Expertopinion

Five-yearview

Key issues

Information resources

References

Affiliations

\title{
Selective serotonin reuptake inhibitors in the treatment of generalized anxiety disorder
}

\author{
David Baldwin ${ }^{\dagger}$, Christel Buis and Andrew Mayers
}

Selective serotonin reuptake inhibitors have proven efficacy in the treatment of panic disorder, obsessive-compulsive disorder, post-taumatic stress disorder and social anxiety disorder. Accumulating data shows that selective serotonin reuptake inhibitor treatment can also be efficacious in patients with generalized anxiety disorder. This review summarizes the findings of randomized controlled trials of selective serotonin reuptake inhibitor treatment for generalized anxiety disorder, examines the strengths and weaknesses of other therapeutic approaches and considers potential new treatments for patients with this chronic and disabling anxiety disorder.

Expert Rev. Neurotherapeutics2(5), 717-724 (2002)

\section{Introductory ovenview}

\section{Clinical features \& epidemiology of}

\section{generalized anxiety disorder}

Generalized anxiety disorder (GAD) is characterized by inappropriate or excessive anxiety and worrying that is persistent and not restricted to particular circumstances. Common symptoms include:

- Apprehension, with worries about future misfortune

- Inner tension and difficulty in concentrating; motor tension, with restlessness

- Tremor and headache

- Autonomic anxiety, with excessive perspiration, dry mouth and epigastric discomfort

The lifetime prevalence in the general population is around $5-6 \%$, the 12 -month prevalence varying according to diagnostic criteria from $1.5 \%$ with D iagnostic and Statistical M anual of M ental D isorders IV (DSM -IV) to $3.1 \%$ with D SM -III-R criteria [1]. The age of onset of $G A D$ differs from that with other anxiety disorders, the majority of cases presenting aged around 35-45 years [2-4]. GAD is probably the most common anxiety disorder among the elderly population (55-85 years) [5]. Symptoms fluctuate in intensity over time, but GAD is usually a chronic condition [6]. The functional impairment is similar in magnitude to that with major depression $[3,7]$.
GAD is amongst the most common psychiatric disorders seen in general practice. The point prevalence of ICD-10 defined GAD in European primary care settings was $4.8 \%$ for GAD without other comorbid depressive or anxiety disorders and $3.7 \%$ for GAD with depression: a further $4.1 \%$ had 'subthreshold' GAD [6]. Comorbid GAD is associated with more severe symptoms, greater functional impairment, a more prolonged course, decreased productivity and higher use of health services [6-9]. Comorbid depressive symptoms improve the chances of a patient being recognized as having a psychological problem, though not necessarily GAD [6].

\section{Pathophysiology of generalized anxiety disorder}

Serotonin (5-hydroxytryptamine, 5-HT) is integrally involved in the mediation of anxiety through serotonergic innervation of the limbic system, hypothalamus and thalamus. Levels of the serotonin metabolite 5-hydroxyindoleacetic acid in cerebrospinal fluid are low in patients with $G A D$ - symptoms may be worsened by administration of the $5-\mathrm{HT}_{1} / 5-\mathrm{HT}_{2}$ receptor agonist, m-chlorophenylpiperazine; and patients with GAD show a reduction in binding of the selective serotonin reuptake inhibitor (SSRI) paroxetine to platelets [10]. Disturbances of the noradrenergic system are 
also likely to be important: in GAD patients, challenge with the $\alpha_{2}$ receptor antagonist yohimbine produces little increase in plasma 3-methoxy-4-hydroxyphenylglycol, compared with that seen in healthy controls [11]. Further evidence for a role of noradrenergic disturbance comes from the observation that ${ }^{3} \mathrm{H}$-yohimbine binding to platelets is reduced, compared with that in controls or patients with major depression [12]. Finally, the GABA/benzodiazepine system is also implicated in the pathophysiology of GAD: untreated patients have a reduced number of platelet membrane benzodiazepine binding sites, the number increasing after diazepam treatment - an investigation of lymphocyte membrane benzodiazepine binding sites produced similar findings [13,14]. Further evidence of a role for disturbances of these systems in the pathophysiology of GAD comes from treatment studies involving certain SSRIs, the serotonin-norepinephrine reuptake inhibitor venlafaxine, certain benzodiazepine anxiolytics and the novel anxiolytic pregabalin.

\section{Treatment with selective serotonin reuptake inhibitors Citalopram}

N o controlled trials with citalopram have yet been presented or published. An early randomized controlled trial comparing two dose ranges of citalopram and imipramine in 472 primary care depressed patients found that both treatments produced reduced mean scores on the $\mathrm{H}$ amilton $\mathrm{R}$ ating Scale for $\mathrm{D}$ epression (H AM D) anxiety factor [15]. A more recent study comparing citalopram and paroxetine in 104 patients with DSM -IV major depression or mixed anxiety-depressive disorder found that both treatments were associated with significant reductions in the H AM -A total score [16]. By contrast, the results of a 24week, double-blind, placebo-controlled treatment study comparing citalopram and sertraline in 323 patients with D SM -IV major depressive disorder indicate that citalopram was more efficacious than placebo in reducing mean scores on the HAM D anxiety cluster $(p<0.01)$, there being no significant difference on this measure between sertraline treatment and placebo [17].

\section{Escitalopram}

Citalopram is a racemic mixture of two enantiomers, of which only the S-isomer (escitalopram) has significant serotonin reuptake inhibitory properties [18]. Escitalopram is more selective and more potent than citalopram and has been found to be more efficacious than the parent compound in a pooled analysis of randomized controlled trials in patients with major depressive disorder [19]. Preliminary data in patients with GAD indicate that escitalopram is significantly more efficacious than placebo and an extensive clinical trial program is underway in this area [20].

\section{Fuoxetine}

There are no published treatment studies in adults with D SM IV GAD. An open pilot treatment study in 16 children and adolescents (9-18 years) with mixed anxiety disorders showed that fluoxetine might be of only limited benefit [21]. Double blind treatment studies in depressed patients indicate that fluoxetine is as efficacious as imipramine, clomipramine or amitriptyline in relieving anxiety symptoms in depression, but the efficacy of fluoxetine in comorbid depression and GAD is not proven [22].

\section{Fuvoxamine}

The efficacy of fluvoxamine as a treatment for GAD has not been established. However, in a small $(n=30)$ open study of patients with comorbid major depression and GAD, fluvoxamine showed significant improvement in both anxiety and depressive symptoms [23]. This finding requires replication in patients with GAD before the efficacy of fluvoxamine can be assumed.

\section{Paroxetine}

The efficacy of paroxetine in short-term treatment of GAD has been evaluated in four randomized double-blind controlled studies [24]. The first evaluation of paroxetine was in a comparator-controlled trial involving 81 patients with a D SM -IV diagnosis of GAD, paroxetine being compared with imipramine and 2 '-chlorodesmethyl-diazepam in an 8-week treatment study [25]. Paroxetine showed superior efficacy to 2 '-chlorodesmethyldiazepam and similar efficacy to imipramine. Paroxetine treatment differed significantly $(p<0.05)$ from 2 -chlorodesmethyldiazepam from week 4 onwards, while imipramine only did so at study end-point. The second investigation was an 8-week, dose-finding study involving 566 patients, performed in the U SA. In this study, paroxetine treatment (20 or $40 \mathrm{mg} /$ day) was significantly superior to placebo $(p<0.001)$ in reducing both the mean H AM -A total score and the mean scores on H AM -A items 1 (anxious mood) and 2 (tension). Response rates were 68 and $81 \%$ with paroxetine 20 and $40 \mathrm{mg} /$ day, respectively, compared with $52 \%$ of patients in the placebo group (observed case data) (FIGURE 1). By the end of the study, the mean change from baseline on a health-related quality of life questionnaire (EuroQ oL-5D ) and visual analog scale was significantly greater for both paroxetinetreatment groups indicating a significant improvement in quality of life.

The third treatment study was an 8-week, flexible-dose study conducted in 326 US patients with GAD. Paroxetine (20$50 \mathrm{mg} /$ day) was significantly superior to placebo $(p<0.05)$ in reducing mean H AM -A total score and mean scores on H AM -A items 1 and 2 and was generally well-tolerated [26] (FIGURE 2). A fourth study of similar design conducted in 372 patients in Europe has revealed similar reductions in $\mathrm{H} \mathrm{AM}$-A total score and H AM -A items 1 and 2. Paroxetine has recently been found efficacious in long-term treatment, there being significantly ( $p<$ 0.001 ) fewer relapses with paroxetine $(10.9 \%)$ than with placebo $(33.9 \%)$ in a 6-month, relapse-prevention study [27].

The effects of treatment may extend beyond symptom reduction and improved quality of life. A small $(n=29)$ uncontrolled pilot study showed paroxetine treatment was associated with a reduction in maladaptive personality traits with significant decreases in harm avoidance ( $p=0.0001)$ and novelty seeking ( $p$ $=0.006$ ) and a significant increase in self-directedness ( $p=$ 0.0004) [28]. The placebo-controlled paroxetine treatment studies 
also showed that as symptoms of GAD resolve there is an associated improvement in symptom-related disability, assessed using the patient-rated Sheehan Disability Scale (SD S) which covers impairment in social, work and family life. At endpoint in all three studies, a statistically significant difference between paroxetine and placebo was seen in the SDS total score (flexible-dose study 1 difference $=-1.8, p=0.037$; study 2 difference $=-2.4, p=0.001$; fixed-dose study for $20 \mathrm{mg} /$ day regimen, difference $=-3.1, p<0.001$; for $40 \mathrm{mg} /$ day regimen, difference $=-3.6, p<0.001)[29]$.

\section{Sertraline}

No clinical trials of sertraline in the treatment of GAD have been reported. Double-blind treatment studies indicate that sertraline is efficacious in relieving anxiety symptoms within depression and the symptoms and impairment associated with panic disorder, social phobia, post-traumatic disorder and obsessive-compulsive disorder, but its efficacy in GAD cannot be assumed.

Thefindings of the randomized controlled trials with paroxetine indicate that SSRI treatment can be efficacious in GAD. There are many further research needs, such as:

- Establishing the comparative efficacy and acceptability of differing treatments, in both short- and long-term treatment

- Examining the effects of combining SSRI treatment with psychological approaches, such as cognitive-behavioral therapy

- Evaluating the effectiveness of treatment in wider clinical practice

\section{Other treatment approaches \\ Otherantidepressant drugs}

Nefazodone

$\mathrm{N}$ efazodone inhibits the reuptake of both serotonin and norepinephrine, although its strongest action is antagonism of the $5-\mathrm{H} \mathrm{T}_{2 \mathrm{a}}$ receptor. Studies in patients with major depression and associated anxiety indicate that nefazodone can significantly reduce anxiety symptoms and a small open-label evaluation suggests that it can improve the symptoms of GAD [30,31].

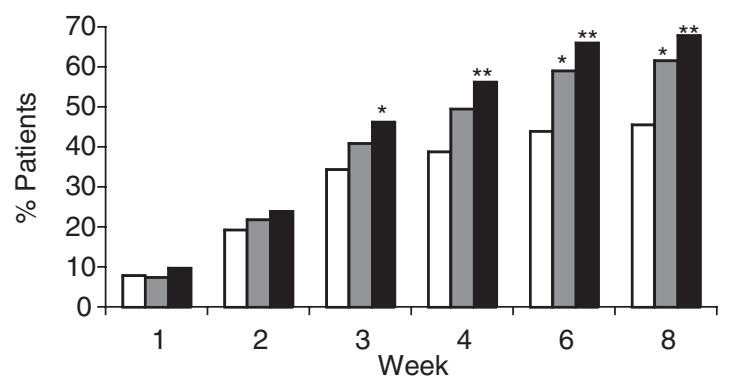

$\square$ Placebo $\square$ Paroxetine $20 \mathrm{mg} /$ day $\square$ Paroxetine 40 mg/day

Figure 1. Reponse to paroxetine treatment in GAD. \% refers to patients fulfilling CGI-I 1 (very much) or 2 (improved) scores. ${ }^{*} p<0.027$ vs. placebo (adjusted for pairwise comparisons), ${ }^{*} p<0.001$ vs. placebo.
Venlafaxine

This serotonin-norepinephrine reuptake inhibitor has proven efficacy in the treatment of depression and GAD. A preliminary study in depressed outpatients indicated that once-daily venlafaxine was efficacious in relieving anxiety symptoms and suggested it might therefore have a role in the management of patients with GAD [32]. This supposition was confirmed by the findings of two studies of short-term treatment of GAD with venlafaxine [33,34]. In one study, venlafaxine was significantly superior to the active comparator buspirone in reducing anxiety symptoms and there was some evidence that venlafaxine had an earlier onset of action [33]. Three other placebo-controlled studies of venlafaxine in the short-term treatment of GAD have been presented $[35,36]$. Efficacy is reported in two of the three studies of venlafaxine compared with placebo, but until these studies are published fully it is difficult to make a detailed assessment.

The long-term efficacy of venlafaxine extended-release capsules has been shown through the results of a 6-month, randomized, double-blind, placebo-controlled, parallel-group study [37]. These 6-month results were replicated in a second placebocontrolled study [38]. The single relapse prevention study, over a period of 4 months, did not show efficacy for venlafaxine, compared with placebo. Evidence supporting a dose- response relationship for venlafaxine is reported in the 6-month studies, with higher doses associated with a better response.

\section{Mirtazapine}

The primary mechanism of action of mirtazapine is through antagonism of presynaptic $\alpha 2$ receptors and heteroceptors. N 0 studies of mirtazapine in GAD have been reported, although a small placebo-controlled study of outpatients with primary anxiety disorders indicated that it could reduce anxiety symptoms and improve overall functioning [39]. A meta-analysis of eight double-blind controlled treatment studies in patients with major depression suggests that mirtazapine is efficacious in reducing anxiety-related items of the HAM D [40].

\section{Other serotonergic drugs}

Buspirone

Buspirone is an azapirone anxiolytic drug, with partial agonist properties at $5-\mathrm{H} \mathrm{T}_{1 \mathrm{a}}$ receptors, which has proven efficacy in the treatment of patients with GAD [41]. An early study established that buspirone had comparable efficacy with diazepam in patients with generalized anxiety and a meta-analysis of eight controlled treatment studies indicates that buspirone has comparable efficacy with benzodiazepines in the management of GAD $[42,43]$. It also appears efficacious in reducing associated depressive symptoms in patients with GAD, but is not an accepted treatment for patients with major depression [44]. However, not all studies with buspirone have been positive [45,46].

\section{Flesinoxan}

Flesinoxan is a related drug, which acts as a full agonist at somatodendritic $5-\mathrm{HT}_{1 \mathrm{a}}$ receptors: it too has been found efficacious 


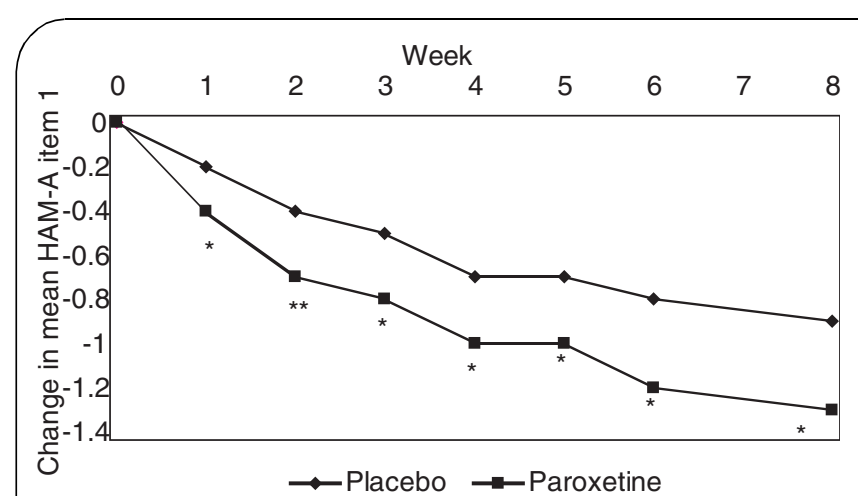

${ }^{*} p<0.05$ versus placebo; ${ }^{* *} p<0.001$ versus placebo
${ }^{\dagger}$ Adjusted for treatment and site
Mean dose at end-point $=34.3 \mathrm{mg} /$ day

Figure 2. Reduction in HAM-A item 1 (anxious mood) during treatment with paroxetine (flexible dose) or placebo.

in the treatment of GAD. A five-arm study comparing three doses of flesinoxan, alprazolam and placebo found that both the highest dose of flesinoxan and alprazolam were significantly more efficacious than placebo in reducing anxiety symptoms, rated by the H AM -A, but there is little further information on the efficacy of the drug [47].

\section{Benzodiazepines}

A systematic review of randomized controlled trials has established that benzodiazepines are an effective and rapid treatment for many patients with GAD [48]. However, the benzodiazepines are far from ideal anxiolytic drugs. The untoward effects of benzodiazepines include: sedation, memory disruption and psychomotor impairment, with an associated increased risk of traffic accidents. 0 ther problems include the development of tolerance, abuse and dependence and withdrawal symptoms on stopping the drug. As such, many authorities counsel that benzodiazepines should be reserved for short-term use (up to 4 weeks) and prescribed at low dosage [49]. 0 thers have argued that benzodiazepines are clearly efficacious and withholding treatment on the basis of potential risk of dependence is unjustified and detrimental to overall well-being [50].

Other potential future approaches to the management of patients with GAD include treatment with subtype selective benzodiazepines, cholecystokinin (CCK) antagonists and the novel drug, pregabalin. There is good evidence for the efficacy of the $\beta$-carboline abercarnil, which acts as an agonist (full or partial, depending on site) at the benzodiazepine-GABA complex [51]. Four placebo-controlled studies have provided evidence for the efficacy of abercarnil in the management of patients with GAD [52-55]. Treatment studies with CCK antagonists have produced disappointing results: a 4-week, multicenter, double-blind, placebo-controlled, parallel-group study with the CCK-B antagonist Cl-988 failed to reveal efficacy, but interpretation of the findings is difficult because of a significant treatment-by-center interaction [56].
Pregabalin

Pregabalin is a novel psychotropic drug with anticonvulsant, anxiolytic and analgesic properties. The mechanism of action is unknown, although it binds to an auxiliary subunit $\left(\alpha_{2} \delta\right)$ of voltage-gated calcium channels, thereby increasing whole brain GABA [57]. In three randomized, double-blind, placebo-controlled treatment studies (two involving an active comparator), pregabalin was significantly more efficacious in relieving symptoms than placebo and had similar overall efficacy to either alprazolam or venlafaxine $[58,59]$. Further studies with pregabalin are nearing completion.

\section{Psychological treatments}

A systematic review of 35 randomized controlled trials has found that cognitive therapy, using a combination of interventions, such as anxiety management training, relaxation, cognitive restructuring and exposure, is more effective than remaining on a waiting list, anxiety management alone, or nondirective therapy [60]. Furthermore, a 1-year follow-up found that cognitive therapy was associated with better outcomes than either analytic psychotherapy or anxiety management training [61].

It is uncertain whether there is an advantage for combining pharmacological and psychological treatment approaches in the management of patients with GAD, over using single approaches alone [62]. In a comparative study of behavior and cognitive therapy in 40 patients with GAD, concomitant treatment with benzodiazepines significantly reduced the proportion of patients with a good outcome ( $8 \%$ with benzodiazepines, $86 \%$ without) [63,64]. By contrast, a 10-week treatment study in general practice patients with GAD found that the combination of diazepam and cognitive-behavioral therapy was more effective than either treatment given alone, in terms of the onset of improvement and clinical response at the end of the study [65].

Larger studies in patients with major depression show that combining antidepressant drugs with cognitive therapy may besignificantly more effective than either treatment given alone, but this cannot necessarily be assumed to be the case in patients with anxiety disorders [66]. A recent study found that combination treatment with imipramine and cognitive-behavior therapy was not more effective than either treatment as a monotherapy in the acute treatment of patients with panic disorder, although the addition of cognitive-behavioral therapy to imipramine conferred some advantages in subsequent maintenance treatment [67].

\section{Conclusions}

GAD is a common and often incapacitating medical condition, but many patients are not recognized as suffering from a potentially treatable anxiety disorder. W hilst some tricyclic antidepressants and benzodiazepines have been found efficacious in GAD , tolerability problems and other potential risks limit their long-term use in clinical practice. Buspirone is efficacious, but has limited effects in relieving comorbid major depression. The SSRI paroxetine and the selective norepinephrine reuptake inhibitor (SN RI) venlafaxine have 
proven efficacy in published randomized controlled trials and both have been licensed for the treatment of GAD. There is a need for comparative treatment studies: to establish which drug has the better benefit-to-risk profile in routine clinical practice and to determine the relative efficacy of differing pharmacological and psychological treatment approaches. In view of the chronicity of GAD, studies are needed of the long-term efficacy and tolerability of differing treatments.

\section{Expertopinion}

Due to concerns about benzodiazepines, it seems best for clinicians to use either an SSRI or an SN RI antidepressant, when prescribing for patients with GAD. It may be that an SSRI is better tolerated, but an SNRI is more effective and it could be argued that SN RI treatment should therefore be reserved for those who do not respond to earlier treatment with an SSRI. W hichever class is used, the majority of patients will experience some reduction in symptoms within the first 2 months of treatment. There is good evidence that patients who have responded to acute treatment will continue to improve with treatment over a further 6 months and symptom diminution is often associated with a reduction in the associated social and occupational impairment. Although there is a lack of long-term studies on which to base treatment recommendations, the chronic nature of untreated GAD and the risk of developing comorbid depression suggest that treatment should continue for many years.

\section{Five-year view}

The next 5 years should see much further research into the pathophysiology and treatment of GAD. Clinical trial programs will be facilitated by the development of a GAD -specific rating scale and by the production of clear guidelines for establishing the efficacy of putative treatments for the disorder [68]. Neuropsychological testing may indicate who is likely to respond to drug treatment and who to psychological treatment. The efficacy of the SSRI escitalopram may well have been confirmed. $\mathrm{New}$ potential treatment approaches may include use of the $5-\mathrm{H} \mathrm{T}_{2 \mathrm{a} / 2 \mathrm{c}}$ antagonist deramciclane, or the anticonvulsant drug pregabalin. D rugs that act only on particular benzodiazepine receptor subtypes may well be in the late stages of development.

\section{Information resources}

For those with a particular interest in anxiolytic drug development, two books are likely to especially helpful. The first is Anxiolytic Compounds. Perspectives in D rug D evelopment (Wiley) by $\mathrm{N}$ eil Cutler, John Sramek and N eil Kurtz, the second is Anxiolytics (Birkhauser), edited by M ike Briley and David Nutt. There are many websites concerned with anxiety and its treatment, but the quality of these sites is highly variable.

\section{Acknowledgements}

This paper is based partly upon a talk at the Second International Forum in Mood and Anxiety Disorders, held in M onte Carlo, M onaco in N ovember 2001.

\section{Key issues}

- Generalized anxiety disorder (GAD) is a common and often incapacitating condition.

- The pathophysiology of GAD is not established, but disturbances of serotonergic and noradrenergic neurotransmission and of benzodiazepine receptor function are important.

- The selective serotonin reuptake inhibitor (SSRI) paroxetine has proven efficacy in the short-term treatment of GAD.

- The new SSRI escitalopram shows preliminary evidence for efficacy in GAD.

- The selective norepinephrine reuptake inhibitor (SNRI) venlafaxine is efficacious in both acute and continuation treatment.

- Comparative studies of paroxetine and venlafaxine are needed.

- The effect of combining drug treatment with psychological approaches needs further investigation.

- Many new potential drug treatments will be evaluated over the next 5 years.

- There will be much debate about the benefits and risks of potential long-term treatment.

\section{References}

Papers of special note have been highlighted as:

- of interest

-• of considerableinterest

1 Wittchen HU, Carter RM, Pfisster $\mathrm{H}$. Epidemiology of generalised anxiety disorder in the community and in primary care Neuropsychiatry (In press).

2 Carter RM, W ittchen $\mathrm{H}-\mathrm{U}$, Pfisster $\mathrm{H}$ et al. O ne-year prevalence of subthreshold and threshold DSM -IV generalised anxiety disorder in a nationally representative sample. Depress. Anxiety 13, 78-88 (2001).
3 Wittchen $\mathrm{HU}$, Carter RM, Pfisster $\mathrm{H}$ et al. Disabilities and quality of lifein pure and comorbid generalized anxiety disorder and major depression in a national survey. Int. Clin. Psychopharmacol. 15, 319-328 (2000).

4 Yonkers KA, Dyck IR, Warshaw $M$ et al. Factors predicting the clinical course of generalised anxiety disorder. Br. J. Psychiatry 176, 544-549 (2000).

5 Beekman AT, Bremmer M A, D eeg DJ et al. Anxiety disorders in later life: a report from the Longitudinal Aging Study Amsterdam.
Int. J. Geriatr. Psychiatry 13, 717-726 (1998).

6 Weiller E, Bisserbe JC, M aier W et al. Prevalence and recognition of anxiety syndromes in five European primary care settings. A report from the WHO study on Psychological Problemsin General H ealthcare. Br. J. Psychiatry 173(Suppl. 34), 18-23 (1998).

- Emphasises that anxiety disorders are common in primary care, but recognized only infrequently. 
7 Kessler RC, DuPont RL, Berglund P et al. Impairment in pureand comorbid generalized anxiety disorder and major depression at 12 months in two national surveys. Am. J. Psychiatry 156, 1915-1923 (1999).

8 Greenberg PE, Sisitsky T, Kessler RC et al. The economic burden of anxiety disorders in the 1990s. J. Clin. Psychiatry 60, 427435 (1999).

9 Maier W, Falkai P. The epidemiology of comorbidity between depression, anxiety disorders and somatic diseases. Int. Clin. Psychopharmacol. 14(Suppl. 2), 51-56 (1999).

10 Connor KM, Davidson JRT. Generalized anxiety disorder: neurobiological and pharmacotherapeutic perspectives. Biol. Psychiatry 44, 1286-1294 (1998).

11 Charney DS, Woods SW, Heninger GR. $N$ oradrenergic function in generalized anxiety disorder: effects of yohimbine in heal thy subjects and patients with general ized anxiety disorder. Psychiatry Res. 27, 173-182 (1989).

12 Sevy S, Papadimitriou GN , Surmont DW et al. N oradrenergic function in generalized anxiety disorder, major depressive disorder and healthy subjects. Biol. Psychiatry 25 , 141-152 (1989).

13 Weizman R, TanneZ, Granek M et al. Peripheral benzodiazepine binding sites on platelet membranes are increased during diazepam treatment of anxious patients. Eur. J. Pharmacol. 138, 289-292 (1987).

14 Rocca P, Ferrero P, Gualerzi A \& al. Peripheral-type benzodiazepine receptors in anxiety disorders. Acta Psychiatr. Scand. 84, 537-544 (1991).

15 Rosenberg C, D amsbo N, Fuglum E et al. 1994. Citalopram and imipramine in the treatment of depressive patients in general practice. A Nordic multicentreclinical study. Int. Clin. Psychopharmacol. 9(Suppl. 1), 41-48 (1994).

16 Jefferson J, Greist J. A double-blind comparison of citalopram and paroxetinein the treatment of patients with depression and anxiety. Presented at American College of N europsychopharmacology, San Juan, Puerto Rico, December 10-14, 2000.

17 Stahl S. Placebo-controlled comparison of the selective serotonin re uptake inhibitors citalopram and sertraline. Biol. Psychiatry 48, 894-901 (2000).
18 Hyttel J, Bsego KP, Perregard JA, Sanchez $C$. The pharmacological effect of citalopram resides in the (S)-(t)enantiomer. J. N eural Transm. Gen. Sect. 88, 157-160 (1992).

19 Gorman JM, Korotzer A, Su G. Efficacy comparison of escitalopram and citalopram in the treatment of major depressive disorder: pooled analysis of placebocontrolled trials. CN S Spectrums 7(Suppl. 1), S40-S44 (2002).

20 Davidson J, Bose A, Su G. Escitalopram in the treatment of generalized anxiety disorder. Int. J. Neuropsychopharmacol. 5(Suppl. 1), S214 (2002).

21 Fairbanks JM, Pine DS, Tancer NK et al. $O$ pen fluoxetine treatment of mixed anxiety disorders in children and adolescents. J. Child Adolesc. Psychopharmacol. 7(1), 17-29 (1997).

22 Hurst M, Lamb H M. Fluoxetine: a review of its use in anxiety disorders and mixed anxiety and depression. CN S D rugs 14, 5180 (2000).

23 Sonawalla SB, Spillmann M K, Kolsky AR et al. Efficacy of fluvoxamine in the treatment of major depression with comorbid anxiety disorders. J. Clin. Psychiatry 60(9), 580-583 (1999).

24 Baldwin DS. SSRIs in the treatment of generalised anxiety disorder. In: SSRIsin Depression and Anxi ety. M ontgomery SA, den Boer JA (Eds). Wiley, Chichester, UK, 193-209 (2001).

- Review of evidencesupporting use of SSRI in GAD treatment.

25 Rocca P, Fonzo V, ScottaM et al. Paroxetine efficacy in the treatment of generalized anxiety disorder. Acta Psychiatr. Scand. 95, 444-450 (1997).

26 Pollack M H, Zaninelli R, Goddard A et al. Paroxetine in the treatment of generalized anxiety disorder: results of a placebocontrolled, flexible-dosage trial. J. Clin. Psychiatry 62, 350-357 (2001).

-. Key study showing that SSRI treatment can be effective in GAD .

27 Stocchi G, Nordera G, Jokinen RH et al. Continued benefit of long-term paroxetine treatment for generalised anxiety disorder. Int. J. N europsychopharmacol. 5(Suppl. 1), S213 (2002).

28 Allgulander $\mathrm{C}$, Cloninger $\mathrm{CR}$, Przybeck $T R$, Brandt $L$. Changes on the temperament and character inventory after paroxetinetreatment in volunteers with generalized anxiety disorder. Psychopharmacol. Bull. 34(2), 165-166 (1998).

29 Baldwin DS, McCafferty J, Bellew K et al. Improving the disability and impairment associated with generalised anxiety disorder with paroxetine treatment. Int. J N europsychopharmacol. 5(Suppl. 1), S213 (2002).

30 FontaineR, O ntiveros A, ElieR et al. Double blind comparison of nefazodone, imipramine and placebo in major depression. J. Clin. Psychiatry 55, 234-241 (1994).

31 Hedges DW, Reimherr FW, Strong RE et al. An open trial of nefazodonein adult patients with general ised anxiety disorder. Psychopharmacol. Bull. 32, 671-676 (1996).

32 Feighner JP, Entsuah AR, M cPherson $M K$. Efficacy of once-daily venlafaxine extended release (XR) for symptoms of anxiety in depressed out-patients. J. Affect. Disord. 47, 55-62 (1998).

33 D avidson JR, DuPont RL, H edges D et al. Efficacy, safety and tolerability of venlafaxine extended release and buspirone in out-patients with general ised anxiety disorder. J. Clin. Psychiatry 60, 528-530 (1999).

34 Rickels K, Pollack M, Shechan D et al. Efficacy of venlafaxine extended-release (XR) capsules in nondepressed out-patients with generalised anxiety disorder. Am. J. Psychiatry 157, 968-974 (2000).

35 Salinas E. Placebo-controlled evidence for the use of antidepressants in generalised anxiety disorder. Eur.

N europsychopharmacol. 9(Suppl. 5), S176 (1999).

36 Hackett D, M eoni P, White $C$ et al. Efficacy of short and long-term venlafaxine ER treatment for somatic and psychic symptoms of GAD. Eur. Neuropsychopharmacol. 10(Suppl. 10), S337 (2000).

37 Gelenberg AJ, Lydiard RB, Rudolph RL et al. Efficacy of venlafaxine extendedrelease capsules in nondepressed outpatients with general ised anxiety disorder. JAM A 283, 3082-3088 (2000).

38 Allgulander $C, H$ ackett $D$, Salinas $E$. Venlafaxine extended release (ER) in the treatment of generalised anxiety disorder: twenty-four-week placebo-controlled doseranging study. $\mathrm{Br}$. J. Psychi atry 179, 15-22 (2001). 
39 Sitsen JM A, M oors J. M irtazapine, a novel antidepressant, in the treatment of anxiety symptoms: results from a placebocontrolled trial. D rug Invest. 8, 339-344 (1994).

40 Fawcett J, Barkin RL. M eta-analysis of eight randomised, double-blind, controlled trials of mirtazapine, a novel antidepressant drug. J. Clin. Psychiatry 59, 123-127 (1998).

41 Goa KL, Ward A. Buspirone: a preliminary review of its pharmacological properties and therapeutic efficacy as an anxiolytic. D rugs 32, 114-129 (1986).

42 Goldberg HL, Finnerty RJ. The comparative efficacy of buspirone and diazepam in the treatment of anxiety. Am. J. Psychiatry 136, 1184-1187 (1979).

43 Gammans RE, Stringfellow JC, H vidzos AJ et al. U se of buspironein patients with generalised anxiety disorder and coexisting depressive symptoms: a metaanalysis of eight randomised controlled trials. N europsychobiol. 25, 193-201 (1992).

44 Sramek JJ, Tansman M, Suri et al. Efficacy of buspirone in generalised anxiety disorder with coexisting mild depressive symptoms. J. Clin. Psychiatry 57, 287-291 (1996).

45 Ansseau M, Papart P, Gerard M AA et al. Controlled comparison of buspirone and oxazepam in generalised anxiety. Neuropsychobiol. 24, 74-78 (1990).

46 Rickels K, Schweizer E. The spectrum of generalised anxiety in clinical practice: the role of short-term, intermittent treatment. Br. J. Psychiatry 173(Suppl. 34), 49-54 (1998).

47 Bradford LD, Stevens G. D ouble-blind, placebo-controlled fixed dose study of flesinoxan in generalized anxiety disorder. Am. Coll. Neuropsychopharmacol. 167.

48 Gould RA, Otto M W, Pollack M H et al. Cognitivebehavioural and pharmacological treatment of generalised anxiety disorder: a preliminary meta-analysis. Behav. Ther. 28 , 285-305 (1997).

49 Lader $\mathrm{M} \mathrm{H}$. Limitations on the use of benzodiazepines in anxiety and insomnia: are they justified? Eur.

Neuropsychopharmacol. 9(Suppl. 9), S399S405 (1999).

- H ighlights the potential drawbacks of benzodiazepine treatment of anxiety.
50 Argyropoulos SV, Nutt DJ. The use of benzodiazepines in anxiety and other disorders. Eur. Neuropsychopharmacol. 9(Suppl. 9), S407-S412 (1999).

- Argues that benzodiazepines should not be withheld from chronically ill, substantially disabled patients.

51 Aufdembrinke B. Abercarnil, a new beta carboline, in the treatment of anxiety disorders. Br. J. Psychiatry 173, 55-63 (1998).

52 Ballenger JC, M CD onald S, Noyes $R$ et al. The first double-blind placebo-controlled trial of a partial BZD agonists abercarnil (ZK-112-119) in generalised anxiety disorder. Psychopharmacol. Bull. 27, 171179 (1991).

53 Lydiard RB, Ballenger JC, Rickels K. A double-blind evaluation of the safety and efficacy of abercarnil, al prazolam and placebo in out-patients with generalised anxiety disorder. J. Clin. Psychiatry 58(Suppl. 11), 11-18 (1997).

54 Pollack M H, Worthington JH, M anfro GG et al. Abercarnil for thetreatment of generalised anxiety disorder: a placebocontrolled comparison of two dose ranges of abercarnil and buspirone. J. Clin. Psychiatry 58(Suppl. 11), 19-23 (1997).

55 Small GW, Bystritsky A. D ouble-blind, placebo-controlled trial of two doses of abercarnil for geriatric anxiety. J. Clin. Psychiatry 58(Suppl. 11), 24-29 (1997).

56 AdamsJB, Pyke RE, Costaj et al. A double-blind, placebo-controlled study of a CCK-B antagonist, $\mathrm{ClO}-988$, in patients with generalised anxiety disorder. J. Clin. Psychopharmacol. 15, 428-434 (1995).

57 Field MJ, OlesRJ, Singh L. Pregabalin may represent a novel class of anxiolytic agents with a broad spectrum of activity. $\mathrm{Br}$. J. Pharmacol. 132, 1-4 (2001).

- Description of the preclinical and pharmacological properties of a promising compound for the treatment of GAD.

58 Pande AC, Crockatt JG, Janney C et al. Pregabalin, a novel agent, in the treatment of generalized anxiety disorder. Presented at American Psychiatric Association, San Diego, USA, May 2000.

59 Rickels K, Pollack M H, Lydiard RB et al. Comparison of the efficacy and safety of pregabalin and al prazolam in general ised anxiety disorder. Int. J. N europsychopharmacol. 5(Suppl. 1), S213 (2002).
60 Gould RA, 0 tto MW, Pollack M H, Yap L. Cognitive behavioural and pharmacological treatment of generalised anxiety disorder: a preliminary meta-analysis. Behav. Ther. 28, 285-305 (1997).

61 Durham RC, Fisher PL, Trevling LR \& al. One year follow-up of cognitive therapy, analytic psychotherapy and anxiety management training for general ised anxiety disorder: symptom change, medication usage and attitudes to treatment. Behav. Consult. Psychother. 27, 19-35 (1999).

62 Lader $\mathrm{MH}$, Bond AJ. Interaction of pharmacological and psychological treatments of anxiety. $\mathrm{Br}$. J. Psychiatry 173(Suppl. 34), 42-48 (1998).

63 D urham RC, Turvey AA. Cognitivetherapy versus behaviour therapy in thetreatment of chronic generalised anxiety. Behav. Res Ther. 25, 229-234 (1987).

64 Wardle J. Behaviour therapy and benzodiazepines: allies or antagonists? Br. J. Psychiatry 156, 163-168 (1990).

65 Power KG, Simpson RJ, Swanson V et al. A controlled comparison of cognitivebehaviour therapy, diazepam and placebo, alone and in combination, for the treatment of generalised anxiety disorder. J. Anx. Dis 4, 267-292 (1990).

66 Keller M B, McCullough JP, Klein DN et al. A comparison of nefazodone, the cognitive behavioural analysis system of psychotherapy and their combination for the treatment of chronic depression. N . Engl. J. M ed. 342, 1462-1470 (2000).

67 Barlow DH, Gorman JM, Shear MK, Woods SW. Cognitive-behavioural therapy, imipramine, or their combination for panic disorder: a randomized controlled trial. JAM A 283, 2529-2536 (2000).

68 ECNP Consensus meeting, M arch 2000. Guidelines for investigating efficacy in GAD. Eur. N europsychopharmacol. 12, 8187 (2002).

- The most recent guidelines for evaluating efficacy in GAD treatment.

\section{Affiliations}

- D avid Baldwin, FRCPsych, Senior Lecturer in Psychiatry, Community Clinical Sciences Research D ivision, Faculty of M edicine, H ealth and Biological Sciences U niversity D epartment of M ental $\mathrm{H}$ ealth, Royal South $\mathrm{H}$ ants $\mathrm{H}$ ospital, Southampton SO 14 OYG, UK, Tel.: +44 2380 825533, Fax: +44 2380 234243, dsb1@soton.ac.uk 
Baldwin, Buis \& Mayers

- Christel Buis, M D, Clinical Research Fellow, Community Clinical Sciences Research D ivision, Faculty of M edicine, Health and Biological Sciences $U$ niversity $D$ epartment of $M$ ental $\mathrm{H}$ ealth, Royal South $\mathrm{H}$ ants $\mathrm{H}$ ospital,

Southampton SO 14 OYG, UK, Tel.: +44 23 0802 5545, Fax: +44 238082 4243,

Christel@soton.ac.uk

- Andrew Mayers, BSc, Research Psychologist, Community Clinical Sciences Research D ivision, Faculty of $\mathrm{M}$ edicine, $\mathrm{H}$ ealth and Biological Sciences $U$ niversity $D$ epartment of $M$ ental $\mathrm{H}$ ealth, U niversity of Southampton, Royal South $\mathrm{H}$ ants $\mathrm{H}$ ospital, Brintons Terrace, Southampton, UK, SO 14 OYG, Tel.: +44 238082 5541, Fax: +44 238023 4243, a.g.mayers@soton.ac.uk 